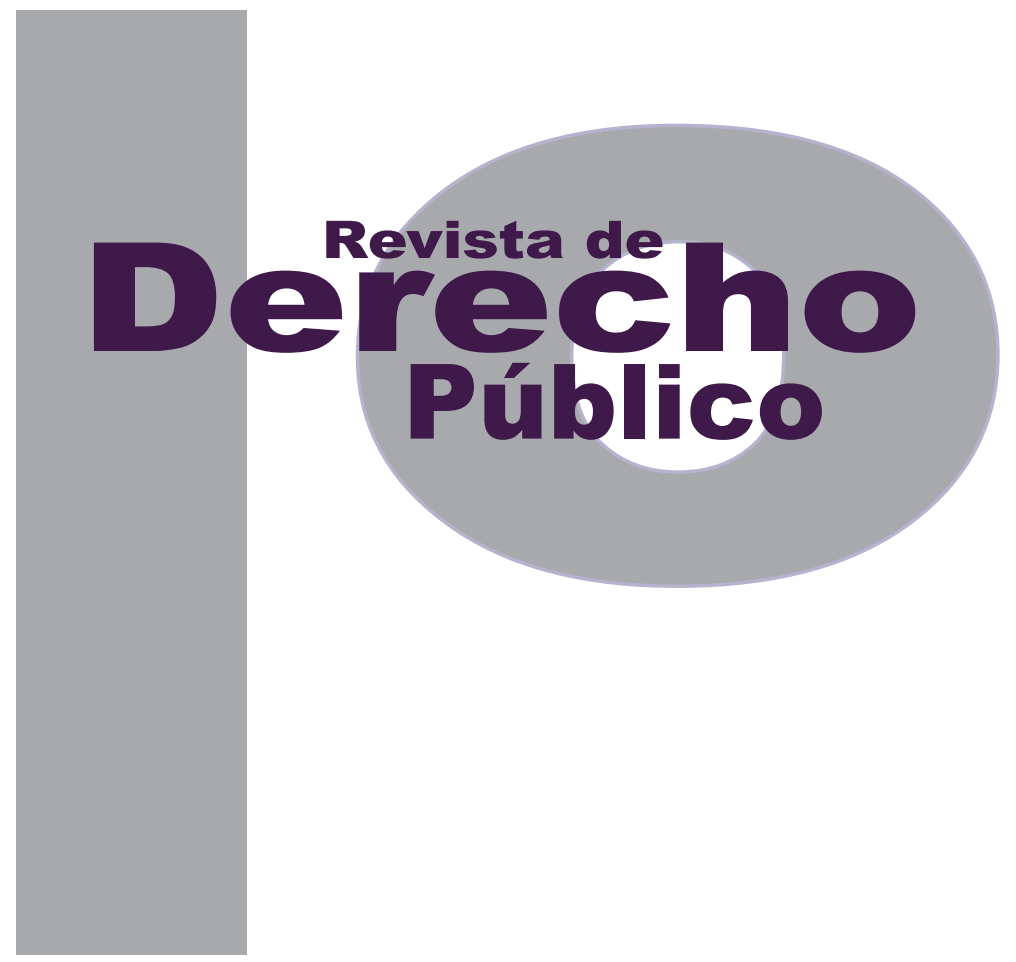

\title{
REPRESENTATIVIDAD PARLAMENTARIA: ¿CONGRESO EN CRISIS?
}

\section{Guillermo Poveda Cubillos}

Revisión de tema

Universidad de los Andes

Facultad de Derecho

Revista de Derecho Público N. ${ }^{\circ} 32$

Enero - Junio de 2014. ISSN 1909-7778 


\section{Representatividad parlamentaria: ¿Congreso en crisis?}

\section{Resumen}

En el presente artículo se analiza la función de representación en el Congreso de la República de Colombia. Concretamente, se encuentra que dicha labor no fue cumplida en anteriores marcos legales y constitucionales, pero tampoco se ve satisfecha en el actual contexto jurídico y político colombiano. Además, se determina que el incumplimiento de la función representativa tiene una fuerte incidencia en el funcionamiento de la rama legislativa. Así, se concluye que el Congreso está en crisis en cuanto a representatividad política, y se plantean algunas posibles soluciones a esta problemática.

Palabras clave: Democracia, función representativa, representatividad política, legitimidad, estabilidad, constitucionalismo.

\section{Political representation: Congress in crisis?}

\section{Abstract}

This article analyzes the representative function of Colombian Congress. Concretely, it finds that this labor hasn't been accomplished in preceding legal and constitucional boundaries, but neither it is been executed at the present time. Besides, it determines that executing this representative function really affects Congress's fulfillment. Thus, this article finds that the Congress faces a crisis regarding its political representation, and proposes some possible solutions to fix it.

Keywords: Democracy, representative function, political representation, legitimacy, stability, constitucionalism.

\section{Representatividade parlamentária: Congresso em crise?}

\section{Resumo}

No presente artigo é analisada a função de representação no Congresso da República da Colômbia. Concretamente, encontra-se que tal labor não foi cumprido em anteriores marcos legais e constitucionais, mas também não é visto como satisfeito no atual contexto jurídico e político colombiano. Além disso, determina-se que o incumprimento da função representativa tem uma forte incidência no funcionamento do ramo legislativo. Assim, conclui-se que o Congresso está em crise quanto a representatividade política, e são apresentadas algumas possíveis soluções a esta problemática.

Palavras-chave: Democracia, função representativa, representatividade política, legitimidade, estabilidade, constitucionalismo. 


\section{SUMARIO}

Introducción - I. FUNCIÓN DE REPRESENTACIÓN: DESARROLLO TEÓRICO - II. REPRESENTACIÓN DEMOCRÁTICA: DE LA TEORÍA A LA PRÁCTICA - A. Constitución Política de 1886: Congreso, ¿representativo o no? - B. Constitucionalismo equilibrado: nuevas garantías a la representatividad - $C$. Diferente escenario: mismos resultados - III. IMPACTO DE UNA DEFICIENTE FUNCIÓN DE REPRESENTACIÓN - A. Percepciones populares relevantes - B. Apreciaciones técnicas: estabilidad en riesgo - C. Elementos adicionales: fragmentación partidaria y circunscripciones especiales - IV. SOLUCIONES A LA VISTA: PROPUESTAS CONCRETAS - V. CONCLUSIONES - Referencias. 


\title{
Representatividad parlamentaria: ¿Congreso en crisis? ${ }^{1}$
}

\author{
Guillermo Poveda Cubillos²
}

Introducción

Desde su remota creación, los cuerpos legislativos han despertado diversas pasiones, divididas entre los que alaban a la institución democrática y los que guardan ciertas reservas sobre su funcionalidad. Dentro del segundo grupo, las críticas se han enfocado -entre otros aspectos- en las labores del órgano legislativo y su deficiente cumplimiento de estas.

Este artículo de reflexión pretende dar cuenta de una labor del Congreso en específico: Ia función de representación política. Concretamente, se busca dar respuesta a un interrogante principal: si puede decirse que el poder legislativo colombiano atraviesa una crisis de representa-

1 Cómo citar este artículo: Poveda Cubillos, G. (Junio, 2014). Representatividad parlamentaria: ¿Congreso en crisis? Revista de Derecho Público, 32.

2 Estudiante de pregado de la Facultad de Derecho de la Universidad de los Andes. Simultáneamente cursa las opciones en Economía y en Periodismo dentro de la misma institución. tividad democrática, y si tal problemática pone en peligro el buen funcionamiento del Congreso.

Para conseguir lo anterior, se comienza evidenciando el desarrollo teórico de la función de representación. Luego, se abordan las críticas al cumplimiento de dicha función por parte del Congreso colombiano desde dos momentos: el primero en vigencia de la Constitución de 1886; el segundo desde la promulgación de la actual Carta Política. Posteriormente, se evalúa qué tanto influye -en términos de legitimidad y estabilidad- una deficiente labor representativa en el funcionamiento del Congreso de la República.

Para ello se tienen en cuenta algunas manifestaciones populares al respecto, junto con opiniones de expertos en la materia. Finalmente, se expone: 1) una conclusión presentando un diagnóstico del estado de la rama legislativa en Colombia en materia de representatividad política, 2) posibles formas de abordar la problemática que se ponga en evidencia. 


\section{FUNCIÓN DE REPRESENTACIÓN: DESARROLLO TEÓRICO}

Diversos autores han abordado la función representativa como una labor esencial de los órganos legislativos. Desde la época de la llustración, destacados pensadores se han manifestado sobre la representación, atribuyéndole significados sencillos pero muy dicientes. A manera de ejemplo, Jean Jacques Rousseau, citado por Berlín Valenzuela, la ha definido como "la forma de resolver los problemas de muchos por unos cuantos", de instituir a un grupo determinado confiriéndole la voz del pueblo (Berlín Valenzuela, 1993, p. 130).

Asimismo, teóricos como Montesquieu (1977) han creado nexos directos entre el actuar del sujeto elegido por el pueblo y las conductas del electorado mismo. El filósofo argumenta que los actos cumplidos por los representantes -el legislador- deben considerarse como hechos por el mismo representado; es decir, por los electores que lo empoderan. Por otro lado, el constitucionalista James Madison daba alta trascendencia a las inquietudes del electorado. Consideraba que "el principio que exige que los representantes conozcan (y atiendan) los intereses de sus electores es tan fundado como importante" (Hamilton, Madison y Jay, 1943, p. 239).

De igual manera, algunas teorías democráticas han considerado que "nuestros líderes de la Independencia adoptaron la representación política popular como una manera efectiva de ga- rantizar los derechos y libertades ciudadanas" (Herrera LLanos, 2003, p. 5).

En tiempos más recientes, teóricos como el jurista Norberto Bobbio han evidenciado la relevancia que se ha dado a la figura del legislador como sujeto representativo. Tanto así que se han creado categorías específicas para diferenciar entre los distintos tipos de representante. El autor distingue varias figuras, entre las que se destacan: 1) el representante delegado, al que se imponen límites en su labor; 2) el representante de intereses particulares, que aboga por las causas de grupos, clases o gremios y 3 ) el representante fiduciario o de confianza, al que se confiere cierta libertad, pues se supone interpreta acertadamente los intereses generales de la sociedad (citado por Burgos, 2000, p. 41).

Por su parte, Berlín Valenzuela (1993, p. 130) ha afirmado que "entre las funciones parlamentarias la representativa es primordial, ya que entre las variadas actividades del parlamento ésta es una constante sobre la que encuentran su base las demás (funciones)". Este catedrático resalta lo oportuna que resulta la función de representación, debido a una serie de factores cualitativos y cuantitativos que hacen imposible que las mayorías de una nación acudan a reunirse para participar en la elaboración de las leyes o en la toma de decisiones que afectan a la población (p. 130).

Por un lado, él entiende como factor cualitativo lo complejo que resultaría el que la ciudadanía en su conjunto se dedicase a legislar, dejando de lado su trabajo y demás formas de subsis- 
tencia. Por otro lado, el factor cuantitativo hace referencia a lo engorroso que resultaría reunir multitudes numerosas, dando la oportunidad a cada parcitipante de expresar su consentimiento u oposición frente a la adopción de cualquier medida legislativa. Así las cosas, Berlín considera al legislador como un vehículo de expresión de intereses, un mandatario que obedece y habla en nombre de su mandante (1993, p. 130). También le atribuye una función social específica, entendiéndolo como ese sujeto que mediante el diálogo y el debate evita la generación de conflictos, y aun la violencia misma (p. 131).

Incluso, algunas corrientes económicas han otorgado un carácter técnico a las relaciones entre electores y elegidos. El economista Joseph Schumpeter considera a estos últimos como "élites de expertos en materia política, capaces de descubrir a los ciudadanos lo que en realidad desean" (1971, p. 332), y a los órganos democráticos -entre estos el Congreso- como mecanismos estabilizadores donde los ciudadanos eligen entre las élites de expertos, aquella que mejor representará y satisfará sus deseos ( $p$. 332).

Autores como Gregorio Peces-Barba (1986, p. 213) conciben la rama legislativa como el único sistema capaz de resolver enfrentamientos "no con el exterminio del adversario, sino a través de la regla de las mayorías". Por su lado, Berlín Valenzuela va más alla al introducir al pluripartidismo como elemento indispensable para cumplir cabalmente con la función representativa del Congreso. Asegura que un buen parlamento debe evitar que "sólo una clase, estamento, gre- mio o grupo ideológico acumule o monopolice la representatividad", con el fin de no soslayar las minorías (1993, p. 132).

Un último punto tratado también por Berlín Valenzuela introduce un elemento que será relevante en el análisis a desarrollar en líneas posteriores: la receptividad parlamentaria a nuevas demandas (1993, p. 134). El autor considera a este atributo indispensable para el buen funcionamiento de un órgano legislativo que atienda a las necesidades cambiantes del pueblo soberano.

Paralelamente, el autor Pablo de Bufalá (2010) da un enfoque distinto a la función de representación, adicionando a lo ya planteado por Berlín Valenzuela un tercer sujeto dentro de la relación elegido-elector: la administración o poder ejecutivo. Considera que la función de representación “implica a menudo un aspecto de limitación del poder gubernamental y sus políticas" (p. 5). En términos aún más prácticos, el autor define al legislador como el mediador entre el ciudadano y la administración, y de forma similar a la que Berlín Valenzuela introduce el elemento de pluralidad en la función representativa, da preponderancia a la oposición como actor indispensable en la dinámica legislativa. Asegura además que el parlamento funge como tribunal que confiere acceso fácil y franco a esta oposición, velando así por la representatividad de las minorías (p. 5).

Por su parte, Bobbio define a la función representativa como el mecanismo mediante el cual las deliberaciones colectivas que involucran a 
todo el cuerpo social no son tomadas directamente por quienes forman parte de él, sino por personas elegidas para este fin (1994, p. 34). En este punto cobra relevancia lo expuesto por el autor Vladimiro Naranjo, quien confiere implicaciones importantes a la noción de representatividad democrática, y agrega que el parlamento, "como cuerpo de representación popular que es por excelencia", debe ser un espacio abierto al pueblo que lo instituyó (2000, p. 259).

Concretamente, Naranjo defiende la publicidad de los actos parlamentarios, pues en últimas constituyen decisiones de quienes representan al pueblo, quien merece conocer tanto los aspectos procesales como sustanciales de dichas medidas legislativas.

Para abordar el siguiente punto, y luego de estas apreciaciones neutrales, cabe mencionar una última aproximación teórica a la representación dentro de los órganos legislativos, esta vez con un fuerte contenido crítico. Corresponde al filósofo y teórico del derecho Carl Schmitt, quien estaba convencido de que el parlamento, lejos de representar la voluntad popular, estaba controlado por grupos de interés antagónicos y bloques poderosos que representaban diferentes segmentos de una sociedad dividida, cuyo interés principal no era defender los ideales del pueblo que lo había elegido (1926, p. 6).

\section{REPRESENTACIÓN DEMOCRÁTICA: DE LA TEORÍA A LA PRÁCTICA}

Dentro de las labores sobre las que recae la crítica a los cuerpos legislativos en Latinoamérica, principalmente se encuentran: la función deliberativa, la función legislativa, la función representativa y la función de control a las finanzas públicas, entre otras. ${ }^{3} \mathrm{~A}$ lo largo de los años, en particular, el Congreso colombiano ha sido objeto de numerosos cuestionamientos, enfocados precisamente en el ineficiente o algunas veces nulo cumplimiento de sus funciones como rama legislativa.

Pero, tal vez, la labor que más ha suscitado críticas en Colombia ha sido la función representativa. Las posiciones críticas sobre el particular han sido sustentadas por diversos sectores de la sociedad: desde reputados académicos hasta personajes de la vida política, entre ellos los propios congresistas.

Con miras a hacer de este un análisis integral, se evalúa la función de representación para el caso colombiano, en el marco de los dos últimos ordenamientos constitucionales. Esto, con el fin de evidenciar las variaciones presentes en cada momento, para así concluir sobre la situación actual de la representación política en Colombia.

3 Según lo expone el autor Francisco Berlín Valenzuela, en el texto aquí citado. 


\section{A. Constitución Política de 1886: Congreso, ¿representativo o no?}

Aun desde antes de la promulgación de la Constitución de 1991, el Congreso ${ }^{4}$ ha estado sujeto a innumerables críticas debido a la alegada falta de representatividad que tiene en relación con el pueblo que lo elige. Para referirnos en concreto a la Constitución de 1886, debe comenzarse por señalar un elemento que pudo haber propiciado dicha ausencia de representatividad: la mínima variedad de opciones políticas con las que contaba el electorado en dicho marco constitucional.

En efecto, el pluralismo partidista no fue una característica histórica de nuestro sistema político, ya que incluso a raíz del Acto Legislativo n. ${ }^{\circ} 08$ de 1905 -que estableció el derecho de representación de las minorías- fue poca la presencia electoral que tuvieron movimientos 0 partidos diferentes al Liberal o al Conservador durante todo el siglo XX (Echavarría, 2009, p. 6). En consecuencia, la función de representación de todas las fuerzas y movimientos sociales en el Congreso resultaba un fin casi inalcanzable, en un escenario donde solo se daba cabida a iniciativas políticas muy limitadas, corriéndose así el riesgo de desconocer los intereses y necesidades de una buena parte de la población colombiana.

De igual manera, para el final del régimen constitucional de 1886 era aún evidente la escasa

4 Así lo reconocía de manera escueta la Constitución Política de Colombia de 1886 en su artículo 58 . representación del electorado en instancias legislativas. Efectivamente, ciertas iniciativas institucionales buscaron sanear dicha falta de representatividad por medio de la creación de órganos transitorios. Es el caso de las Comisiones de Paz que se instauraron -sin participación de la rama legislativa - en el Gobierno de Belisario Betancur (1982-1986). Dichos grupos se constituyeron como un "pequeño parlamento" que pudiera hacer lo que no hacía el Congreso: representar a los diversos sectores de la sociedad (García-Peña, 1993, pp. 45-49).

En el período siguiente al de Betancur, Virgilio Barco creó nuevamente espacios de producción legislativa. En abril de 1989 se instituyeron Mesas de Análisis y Concertación como espacios de amplia representación de los sectores sociales y políticos para elaborar las propuestas de carácter legislativo (García-Peña, 1993, pp. 4549). Esta iniciativa presentó la misma constante que la pasada: la imperceptible participación del Congreso. Vemos así cómo, desde épocas pasadas, se han creado instancias institucionales que excluyen a la rama legislativa de las dinámicas políticas y sociales del país, motivadas en la bajísima capacidad de representación popular de esta.

Adicionalmente, la inestabilidad que caracterizó al anterior marco constitucional -la Carta Política de 1886 estuvo sujeta a más de setenta reformas- pudo haber incidido en el deficiente cumplimiento de la función representativa del Congreso (Banco de la República, 2000, párr. 17). En efecto, este escenario de continuos ajustes constitucionales impedía que la función 
de representación se convirtiese en una constante dentro del articulado constitucional, pues pese a que en algunas reformas dicha labor era reconocida como un fin de las dinámicas electorales, en otras se desconocía y obviaba la función representativa.

Es el caso del Acto Legislativo n. ${ }^{\circ} 03$ de 1954, que reformaba el artículo 15 de la Constitucional Nacional y reconocía clara y expresamente a la representación política como función a desempeñar por quien pretendiese ser elegido para un cargo de elección popular. Sin embargo, el Acto Legislativo n. ${ }^{\circ} 01$ de 1975 reformó nuevamente el artículo 15 constitucional, pasando a obviar dicha función de representación política para referirse, única y escuetamente, al desempeño de empleos públicos como función de quien resultase elegido en las urnas.

En oposición a lo anterior, algunos teóricos consideran que factores ajenos a los congresistas han influido en el ineficiente cumplimiento de la función representativa de estos. En particular, el catedrático Manuel Iturralde opina que durante los estados de sitio que se dieron en Colombia durante la segunda mitad del siglo XX, se interfirió hasta tal punto la labor del legislador que su representatividad se vio seriamente afectada. Afirma, además, que se creó una "cultura de la emergencia, alimentada por una continua percepción social de crisis, que colonizó el poder representativo del Congreso, al remplazarlo durante los estados de excepción, y al querer convertir decretos legislativos de excepción en legislación permanente" (2003, pp. 29-46).
Así las cosas, existen posiciones encontradas acerca de la función de representación ejercida por el Congreso durante la vigencia de la pasada Carta Política. Mientras unos consideran que desde ese entonces la rama legislativa era inoperante en términos de representatividad -bien sea por cuenta de la falta de opciones políticas o de los constantes cambios al articulado constitucional- otros aseveran que esta disfunción se debió a intromisiones de otras ramas del poder público. Ahora se hace necesario analizar la función representativa a la luz de la Constitución Política de 1991, que introdujo nuevas variables a dicha función.

\section{B. Constitucionalismo equilibrado: nuevas garantías a la representatividad}

Aunque la actual Carta Política en su artículo 103 establece una serie de mecanismos de participación democrática para el pueblo, ${ }^{5}$ este - como titular del poder político- elige a sus representantes para efecto de la integración de instituciones políticas con atributos de mando. A partir de lo dicho se considera que el sistema político que rige a Colombia es una democracia indirecta, donde los dirigentes cumplen primordialmente una labor representativa (Burgos, 2000, p. 39).

Actualmente, la función representativa se encuadra en un marco constitucional y legal distinto al presente hace algunos años. Uno de los grandes logros obtenidos por la actual Carta Política se

$5 \quad$ Tales como el voto, el plebiscito, el referendo, la consulta popular, el cabildo abierto, la iniciativa legislativa y la revocatoria del mandato. 
dio en materia de frenos y contrapesos. Para algunos expertos, el mayor logro de la Constitución de 1991 ha sido equilibrar las relaciones entre poderes del Estado, construyendo así un campo más armónico en el ámbito público. Sobre el particular, catedráticos como Helena Alviar y Mónica Pachón coinciden en que es de resaltar la capacidad de la actual Carta Política "para enmarcar y encauzar la pugna entre las tres ramas del poder público dentro de los límites de la institucionalidad" (Bejarano, Alviar, Botero, Hoskin y Pachón, 2010, p. 146).

A manera de ejemplo: la Constitución de 1991 consiguió regular en buena forma los tan criticados estados de sitio amparados por la Carta de 1886, que podían durar hasta treinta años sin ningún tipo de control al poder ejecutivo, en detrimento de las demás ramas del poder público (García y Uprimny, 2006, p. 7). De esta forma, los otrora conocidos como 'estados de sitio' pasaron a denominarse estados de excepción, y tanto su duración como las facultades de la rama ejecutiva se vieron sustancialmente limitadas. ${ }^{6}$ Así las cosas, al menos en este aspecto el Congreso recuperó esa legitimidad y representatividad que algunos toman por usurpada en el marco constitucional pasado.

En este orden de ideas, sería difícil alegar que la crisis de la función de representación se debe a fallas estructurales, como, por ejemplo, un mal diseño constitucional. Expertos en historia política, como el catedrático Daniel García-Peña,

6 En virtud del Título VII, capítulo sexto de la Constitución Política de Colombia de 1991. consideran que "con la Constitución de 1991, el Congreso de la República recibió una gran cantidad de nuevos mecanismos y herramientas que posibilitan asumir su rol constitucional como escenario central de representación de los diferentes sectores sociales y políticos de la nación" (1993, pp. 45-49).

Adicionalmente, algunas normas contemplan los casos en que el Congreso no cumpla con su función como representante de la voluntad general. A manera de ejemplo: la Ley 5 de 1992 -que regula las dinámicas legislativas- en su artículo 7 estipula que los miembros del Congreso, al fungir como representantes del pueblo, deberán actuar consultando la justicia y el bien común; siendo además responsables ante la sociedad y frente a sus electores del cumplimiento de las obligaciones propias de su investidura.

Asimismo, el actual marco constitucional estipula la obligatoriedad del voto nominal y público, gracias al artículo 5 del Acto Legislativo 01 de 2009, el cual cambió en este sentido la dinámica de aprobación de leyes en el Congreso. Según la analista política Marcela Prieto, dicha medida constituyó "un gran avance en términos de la responsabilidad que cada congresista tiene no sólo frente a los postulados ideológicos y programáticos de la colectividad política de la que hace parte, sino también frente al conjunto de ciudadanos que representa" (2010, p. 31).

Vemos así, cómo el Congreso de la República se enfrenta actualmente a creaciones jurídicas que propenden por el cumplimiento de su función representativa. Por un lado, cuenta con un 
marco constitucional que lo respalda, brindándole garantías para ejercer sus labores frente a los demás poderes públicos. Por otro lado, su misma producción legislativa le recuerda su compromiso de no defraudar a sus electores, quienes empoderaron a sus integrantes como dignos representantes de la voluntad general.

\section{Diferente escenario, mismos resultados}

A pesar de esta serie de opciones a disposición del Congreso, desde tiempos pasados algunas variables han incidido en el actuar individual de los congresistas, restringiendo su capacidad de representar al pueblo. El propio García-Peña afirma que desde antes de 1991, los congresistas solo asumían roles a conciencia dentro del proceso legislativo cuando estaban en juego intereses de partido o de carácter personal. El autor afirma que esta inclinación por satisfacer necesidades individuales en lugar de atender a los requerimientos colectivos ha determinado su inefectividad como órgano de representación popular (1993, pp. 45-49).

Lo que resalta es que dicha tendencia no solo se mantiene, sino que ha trascendido de un ordenamiento constitucional a otro. Actualmente, los congresistas colombianos continúan desatendiendo los requerimientos puntuales del pueblo que los empodera. Un ejemplo bastante ilustrativo respaldará esta posición. En el actual período legislativo (2010-2014) se presentó un proyecto de ley que buscaba convertir a la salud en un derecho fundamental. Aun cuando esta iniciativa respondía al llamado de millones de colombianos que demandan un tratamiento jurídico distinto al derecho a la salud -en pro de garantizar su goce efectivo- el proyecto de ley se hundió por una escasa diferencia de votos en contra (Semana, 2012), a pesar de que el grueso de la población colombiana conoce los problemas estructurales que aquejan a nuestro sistema de salud, y se ha puesto de manifiesto la necesidad de que la rama legislativa emprenda acciones para reparar este estado de cosas.

Teniendo en cuenta lo anterior, y retomando lo expuesto en líneas anteriores por Berlín Valenzuela, el buen funcionamiento de un órgano legislativo está mediado por su capacidad de atender a las necesidades cambiantes del pueblo soberano. ${ }^{7}$ En otras palabras, es la receptividad a las nuevas demandas la que determina en buena medida qué tan operante es un cuerpo legislativo. En el caso en comento, el Congreso colombiano ha demostrado una mínima atención a los problemas y demandas planteados por la ciudadanía, poniéndose en entredicho una vez más su función de representación popular.

Por otra parte, aun cuando el cumplimiento de la función representativa se pone a menudo en entredicho, se han presentado intentos políticos por afianzar nuestro sistema democrático representativo, dando prevalencia al poder legislativo. El 31 de mayo de 1993, el entonces representante a la Cámara Jorge Sedano González pre-

$7 \quad$ El carácter soberano del pueblo colombiano es proclamado por el propio texto constitucional en su artículo 3. 
sentó un proyecto de acto legislativo mediante el cual pretendía cambiar el sistema presidencialista por un régimen fundado en el principio de la primacía representativa (López Michelsen, 2004, p. 67). Argumentaba el congresista que dicho principio contenía aspectos del parlamentarismo, como sus controles y equilibrios; y elementos del presidencialismo, como su separación de poderes. Según Sedano, reestructurar nuestro sistema político con base en la primacía representativa fomentaría el desarrollo integral de la nación (López Michelsen, 2004, p. 67).

Sin embargo, las implicaciones de la primacía representativa son mucho más extensas. Esta figura da prevalencia a las formas colegiadas de autoridad sobre las individuales, estableciendo que los 'elegidos' son de mayor rango jerárquico dentro de una esfera de poder (López Michelsen, 2004, p. 68). Se reconocería así, tácitamente, una prelación del poder legislativo sobre el ejecutivo.

Este tipo de iniciativas han dado cabida a fuertes cuestionamientos a la función de representación dentro del Congreso. Por un lado, la aplicación del principio de primacía representativa iría en detrimento del sistema de frenos y contrapesos de los poderes públicos. Por otro lado, no sería sensato instituir un sistema político basado casi en su totalidad en una función -la de representación-que parece demostrar cada vez más su deficiencia. Al respecto, el constituyente Antonio Navarro Wolf considera que sería un error craso dar aplicación a la primacía representativa. Según él, Colombia se ha caracterizado por su desorden y dispersión política, por cuenta de fenómenos como el clientelismo, que han viciado las dinámicas legislativas poniendo en jaque a la función de representación (citado por López Michelsen, 2004, p. 190).

No obstante, todas estas críticas no se han reducido a simples vocerías de la opinión pública. Los mismos congresistas han reconocido los difíciles momentos que atravesó y actualmente atraviesa la función de representación en el Congreso colombiano. La Representante a la Cámara Sandra Ceballos resalta el que los “propios partidos tradicionales hayan aceptado que pasan por profundas crisis de representatividad y legimitidad política" (citada por López Michelsen, 2004, p. 206).

Pero no solo los grandes movimientos políticos en la historia colombiana han visto cuestionada su función de representación. Basta recordar lo ocurrido en el contexto de las elecciones al Congreso de 2006, donde más de un 30\% de los congresistas electos no pudieron terminar sus períodos por presuntos nexos con grupos ilegales de autodefensas, fenómeno conocido como 'parapolítica'. Lo que resalta del caso es que de ese $30 \%$ de congresistas sancionados, el $72 \%$ pertenecía a partidos políticos no tradicionales, entre ellos el Partido de la U, Cambio Radical y Convergencia Ciudadana (López, 2010, p. 4). Para la experta en política Marcela Prieto, esta situación no solo entorpeció el funcionamiento de Congreso, sino que también reforzó los problemas de legitimidad y representación del órgano legislativo frente a sus electores (2010, p. 32). Se observa así cómo el fenómeno de baja representatividad ha tenido un alcance más ge- 
neralizado del que podría llegarse a pensar, sin importar las procedencias partidistas.

Ahora, y tras enunciar diversas críticas a la función de representación en el actual contexto político colombiano, se pasa a evaluar las implicaciones de un cumplimiento insuficiente de la función representativa por parte de la rama legislativa.

\section{IMPACTO DE UNA DEFICIENTE FUNCIÓN DE REPRESENTACIÓN, ¿CONGRESO LEGÍTIMO Y ESTABLE?}

El estudio de la influencia de una deficiente labor representativa en el funcionamiento del Congreso se hace en torno a dos ejes de análisis: legitimidad y estabilidad de la rama legislativa. Así, se determinará qué tanto incide una deficiente función de representación en la capacidad del Congreso para mantenerse estable y legítimo ante el pueblo que lo eligió.

\section{A. Percepciones populares relevantes}

En este punto conviene comenzar el análisis evidenciando la percepción generalizada que tiene la sociedad sobre el Congreso. Puntualmente, se demostrará qué tan representados se sienten los ciudadanos del común por los legisladores que empoderaron, así como qué tan legítimo consideran al órgano legislativo colombiano. Este estudio cobra relevancia en la medida en que representa, por medio de consultas directas, la imagen que tiene el pueblo sobre el cuerpo de representantes que eligió, siendo en últimas esta percepción la que merece mayor atención.

En sondeos realizados por el Proyecto de Opinión Pública de América Latina (LAPOP), se encontraron elementos que dan luces sobre la percepción de la sociedad en relación con la capacidad representativa del Congreso. Además, los resultados de las encuestas de los últimos cuatro años evidencian el estado actual de la relación entre elector y elegido.

Un primer sondeo cuestiona el desempeño general del Congreso, pues solo un 52\% de los encuestados avala la gestión del órgano legislativo (Rodríguez-Raga, 2011, p. 94). De esta percepción se desprenden algunas otras, como la que trató de medir un segundo sondeo en el que se indagó qué tanto creen los colombianos que el presidente debe gobernar ignorando al Congreso. Aun cuando la intensidad de esta creencia ha disminuido gradualmente, Colombia sigue siendo el segundo país en América Latina -después de Ecuador- donde dicha idea goza de mayor difusión (Rodríguez-Raga, 2011, p. 215).

Un tercer sondeo hace referencia a la confianza que el pueblo tiene en sus instituciones. Para 2011, la confianza en el Congreso apenas llegaba al 50\%, mientras que la confianza en los partidos políticos solo alcanzaba el 35\% (RodríguezRaga, 2011, p. 83). Pero tal vez sea la cuarta consulta la que arrojó los resultados más dicientes sobre la función de representación y su percepción dentro de la sociedad en general. Esta investigó sobre si la gente cree que el pueblo debería gobernar directamente, ignorando los 
conductos habituales de intermediación y representación políticas. Colombia es el séptimo país, dentro de una lista de veintidós naciones americanas, donde se comparte de forma más extendida esta idea, superando apenas a naciones como Haití, Bolivia y Ecuador (Rodríguez-Raga, 2011, p. 218).

Estos cuatro sondeos arrojan conclusiones sobre el estado de la legitimidad y estabilidad del Congreso de la República. Resumiendo, se encuentra que casi la mayoría de la ciudadanía considera que el desempeño del Congreso es cuestionable o deficiente, y una misma cantidad de colombianos desconfía del órgano legislativo. Asimismo, una alta cantidad de ciudadanos -en relación con otros países de la región-cree que tanto la intervención habitual del Congreso en el ejecutivo como la figura de la representación política son ineficaces.

Este último punto evidencia la relación estrecha entre un deficiente cumplimiento de la función representativa y una baja legitimidad. En buena medida, el pueblo encuentra que la representación política es una figura totalmente prescindible. A partir de esto, cobra sentido el que la legitimidad del Congreso se vea fuertemente cuestionada a raíz de la desconfianza que genera. En esta lógica, se pone en duda el carácter legítimo de un cuerpo legislativo constituido mediante figuras seriamente cuestionadas por la sociedad, en este caso, su función de representación del electorado.

Luego de evidenciar los problemas de legitimidad que enfrenta el Congreso colombiano, pa- samos a tratar la relación existente entre una insuficiente labor de representación y la estabilidad del órgano legislativo.

\section{B. Apreciaciones técnicas: estabilidad en riesgo}

En este punto se toman como ejemplo dos fenómenos que tienen lugar en el proceso legislativo colombiano, y que son el punto de encuentro y conexión entre representatividad y estabilidad de la rama legislativa. El primero de ellos es el clientelismo; el segundo, la 'personalización de la política'.

Con respecto al clientelismo, expertos en análisis político opinan que esta anomalía "se ha adaptado a diferentes momentos históricos y ha permanecido como una característica central de la vida política colombiana" (Ladrón de Guevara, 2002, p. 321). Asimismo, ha sido tratado como una variable sumamente nociva dentro del contexto democrático del país. Concretamente, se ha denunciado el surgimiento y consolidación de una serie de relaciones políticas asimétricas y particularistas, que están lejos de lograr que el Congreso sea punto de encuentro de intereses del pueblo en general, representando a todo el electorado colombiano (Bejarano et al., 2010, p. 108).

Con respecto a la "personalización de la política', autores como Laura Wills han aclarado que mediante esta práctica “los candidatos enfocan sus estrategias electorales para lograr su propio éxito", alejándose de los intereses tanto de la colectividad de la que hacían parte como del 
electorado mismo (2009, p. 15). Así, los congresistas ya no buscan siquiera beneficiar a sectores reducidos de la sociedad, y sus intereses pasan a enfocarse en su propio beneficio. En este escenario, ya no podría hablarse al menos de representación deficiente o incompleta de la voluntad general; estaríamos ante una ausencia total de representatividad política por parte del Congreso.

En este orden de ideas, es evidente cómo una deficiente capacidad representativa influye -por medio de anomalías como el clientelismo y la 'personalización de la política'- en la estabilidad del Congreso. Un poder legislativo que no represente la voluntad popular en su conjunto será especialmente susceptible a regirse por dinámicas clientelistas, influenciado por intereses individuales que buscan verse satisfechos con la entrega de un voto a cambio de favores puntuales.

Igualmente, aquel correrá el riesgo de caer en situaciones donde cada congresista actúe en pro de su propio beneficio, por ejemplo, la permanencia en el Congreso o comisiones extralegales. Así las cosas, resulta complejo considerar estable y sólida a una rama legislativa que se debate en todo momento entre representar los intereses generales del electorado o favorecer aspiraciones individuales por medio de fenómenos como el clientelismo.

\section{Elementos adicionales: fragmentación partidaria y circunscripciones especiales}

Como último punto de análisis, este fragmento abordará dos problemáticas que ilustran nueva- mente la incidencia de una deficiente función representativa en la legitimidad y estabilidad del Congreso. La primera es la fragmentación partidaria, y aludirá a la estabilidad de la rama legislativa. La segunda es la ineficacia de las circunscripciones especiales, y referirá a la legitimidad del Congreso.

Con respecto de la fragmentación dentro del poder legislativo, esta anomalía hace referencia a la división intrapartidaria de las fuerzas políticas, y al igual que el clientelismo, es elemento donde confluyen y se relacionan representatividad y estabilidad del Congreso. Esta fragmentación impide que las bancadas promuevan intereses colectivos, entorpeciendo la labor de representación de la voluntad general (Wills, 2009, p. 25).

Dicho fenómeno va en contravía de la estabilidad de la rama legislativa en dos sentidos. Primero, fracciona las fuerzas políticas que interactúan dentro de él, impidiendo que el Congreso tenga un funcionamiento sólido y fluido. Segundo, hace que estas mismas fuerzas vayan en direcciones opuestas, creando escenarios de inconsistencia e inconcordancia entre las iniciativas legislativas. Así las cosas, vemos cómo -a la luz de la fragmentación partidaria- los problemas de representavidad van directamente en detrimento de la estabilidad y solidez del poder legislativo.

El segundo elemento alude a la ineficacia de las circunscripciones especiales en el Congreso de la República. Aun cuando la función representativa busca atender a la sociedad en su conjunto, 
existen sectores determinados en los que dicha función debería cumplirse aún con más eficacia. Ejemplo de esto son los grupos étnicos minoritarios, como los indígenas y afrocolombianos.

El artículo 171 constitucional consagra la circunscripción nacional especial para comunidades indígenas, dando cabida en el Senado a dos líderes elegidos en dichas circunscripciones. De igual manera, el artículo 176 de la Constitución establece la misma figura de circunscripciones especiales en la Cámara de Representantes. La Carta Política reconoce, entonces, que la función de representación se hace extensiva a las comunidades indígenas, cuyos líderes en el Congreso deberán representar los intereses de sus grupos étnicos.

Sin embargo, y aun cuando estas colectividades han gozado de especial protección constitucional, 8 la representación identitaria que se tuvo en mente al instituir la figura de la circunscripción especial no se ha cumplido cabalmente. De acuerdo con la historiadora y politóloga Marcela Escandón, la falta de regulaciones rigurosas es el principal factor de desconexión entre los partidos por comunidades especiales y el resto del sistema político. Como ejemplo, Escandón menciona un fenómeno donde la falta de reglamentación ha permitido que candidatos y organizaciones de bolsillo, sin interés en las comunidades especiales, puedan competir para ganar una curul por estas colectividades (2011, p. 32).

8 Tal como lo consagran los artículos 1,2 y 7 de la Carta Política de 1991.
Como consecuencia de lo anterior, el desempeño electoral de algunas comunidades especiales ha sido paupérrimo, al no sentir estas una verdadera representación de sus intereses por parte de sus elegidos. A manera de ejemplo, basta mencionar lo ocurrido en Guainía en las elecciones al Congreso del año 2010. A pesar de que el departamento cuenta con un 33\% de población indígena, sus comunidades especiales presentaron un abstencionismo de más del 95\% en las contiendas electorales (Escandón, 2011, p. 38).

En estos contextos de desregulación y desincentivos, resulta verdaderamente complejo crear espacios de representación identitaria entre comunidades especiales y terceros que pretenden representarlas, sin tener la intención real de contribuir a sus intereses. Lo demuestra la bajísima participación democrática de grupos étnicos que, a pesar de contar con un marco legal favorable, no ven materializados los mandatos constitucionales que quisieron incorporarlos a las dinámicas legislativas.

\section{SOLUCIONES A LA VISTA: PROPUESTAS CONCRETAS}

En atención a esta serie de falencias en cuanto a representatividad política, a continuación se plantea un conjunto de alternativas de carácter legal e institucional que mejoren el estado de cosas actual.

En primer lugar, se propone la creación de normatividades específicamente encaminadas a 
garantizar el cumplimiento de la función representativa en el Congreso. Tal como se viene argumentando, ni siquiera dentro del actual marco legal la representatividad política ha conseguido afianzarse en la escena pública colombiana.

Normas como la misma Ley 5 de 1992, que regula el funcionamiento y organización del Congreso, se han mostrado insuficientes para los propósitos en cuestión. Aunque en su artículo 7 dicha ley aborda la representavidad política, lo hace de un modo general y abstracto, con un enfoque sumamente dogmático. Esta disposición afirma que "los miembros del Congreso representan al pueblo, y por tanto deberán actuar consultando la justicia y el bien común".

Como se observa, esta norma devela algunas directrices o principios que deben regir la función de representación, pero no ahonda en la manera como se deben cumplir dichos postulados. Brinda un marco general sobre la labor representativa, pero no ofrece elementos para materializar dicho ideal democrático. En este sentido, se sugiere la puesta en marcha de arreglos legales que ataquen los problemas de fondo que entorpecen la representatividad del Congreso. A manera de ejemplo: podrían normativizarse mecanismos de control estricto al actuar de los congresistas, dando especial atención a conductas como el clientelismo y la fragmentación partidaria, que han demostrado amenazar directamente la función de representación.

En segundo lugar y complementando lo anterior, se propone la consolidación de sondeos a nivel nacional donde se escrute - de manera regu- lar- la percepción de la ciudadanía en cuanto a representatividad política. Concretamente, se sugiere la creación y aplicación de encuestas, de un modo mucho más constante y completo que el actual, con el fin de obtener resultados periódicos y realmente dicientes sobre el estado de la función de representación. De esta forma se obtendrían dos beneficios concretos. Por un lado, se conocería de propia voz de la ciudadanía las percepciones generales sobre el funcionamiento del órgano al que el mismo pueblo empoderó. Por otro lado, y en caso de no conseguirse los resultados esperados, la opinión pública empezaría a presionar de manera constante al legislativo, reclamando en todo momento por un cumplimiento óptimo de la función representativa.

Adicionalmente, se propone el fortalecimiento de las veedurías públicas sobre la función de representación, permitiéndose así que la ciudadanía tome lugar activo en el proceso de resolución de esta problemática. Esta sería una etapa posterior a los sondeos o encuestas ciudadanos, una fase complementaria donde el pueblo pase de las meras opiniones y consideraciones a participar en un escenario en el que pueda proponer alternativas de fortalecimiento a la función representativa.

\section{CONCLUSIONES}

En seguida se recogen las siguientes apreciaciones a manera de conclusiones. En primer lugar, se resalta la importancia que ha cobrado la función de representación desde la creación de los 
primeros modelos democráticos, sin importar el contexto político y social donde se hayan instituido. En este sentido, se recalca la relevancia de un exitoso e integral cumplimiento de la labor representativa, particularmente, dentro del Congreso colombiano, con miras a fortalecer y legitimar las dinámicas políticas en nuestro país.

En segundo lugar, se encuentra que las deficiencias en la función de representación no son un fenómeno nuevo para la realidad política colombiana, pues dichas debilidades han sido una constante dentro de nuestros dos últimos marcos constitucionales. En efecto, los electores en general no sentían, ni sienten actualmente que quienes están legislando para ellos hablen o actúen en su nombre, es decir, no consideran que representen sus intereses y necesidades. Esto se debe principalmente a que los congresistas no están siendo receptivos frente a las demandas esenciales en cabeza del pueblo, pues en muchas ocasiones buscan satisfacer únicamente sus intereses individuales. También llama la atención el que esta crisis de representatividad se presente dentro de la rama legislativa en general, sin distinguir entre movimientos políticos tradicionales o colectividades recientemente creadas.

A su vez, lo anterior se traduce en una desconfianza persistente de parte del electorado hacia el órgano legislativo en conjunto. A ello se suman fenómenos como el clientelismo y la fragmentación partidaria, los cuales contribuyen a la crisis de representatividad, creando un nexo entre esta problemática y una deficiente legitimidad y estabilidad de la rama legislativa.
Adicionalmente, este incumplimiento de la función de representación se ha hecho extensivo a los grupos étnicos y minorías políticas que no ven plasmadas en las dinámicas legislativas sus necesidades e intereses, los cuales deberían ser objeto de especial atención dentro de nuestro actual marco constitucional.

En este orden de ideas, se propone la creación de normatividades que materialicen y puntualicen la función representativa del Congreso, señalando mecanismos para el cumplimiento de dicha labor. Asimismo, se plantea la realización de sondeos y escrutinios constantes a la labor legislativa, junto a la instauración de veedurías públicas específicamente encaminadas a evaluar el cumplimiento de la función de representación por parte del poder legislativo.

La propuesta de estos arreglos legales e institucionales cobra sentido únicamente si dichas reformas están inequívoca y exclusivamente enfocadas en el cumplimiento cabal de la función representativa. Solo así estaremos más próximos a una democracia, si bien no perfecta, mucho más cercana a la sociedad en general, así como a la atención de sus intereses y necesidades como pueblo soberano.

\section{Referencias}

Banco de la República. (2000). Constituciones que han existido en Colombia. Recuperado de http://www.banrepcultural.org/ blaavirtual/ayudadetareas/poli/poli57.htm

Bejarano, A., Alviar, H., Botero, F., Hoskin, G. y Pachón, M. (2010). Colombia: una democra- 
cia amenazada. En M. Cameron y J. P. Luna. (Eds.), Democracia en la región Andina: diversidad y desafíos. Lima, Perú: Instituto de Estudios Peruanos.

Berlín Valenzuela, F. (1993). Derecho Parlamentario. México D. F.: Fondo de Cultura Económica.

Bobbio, N. (1994). El futuro de la democracia. Bogotá, Colombia: Fondo de Cultura Económica.

Burgos, J. (2000). Teoría democrática actual: de la representación a la deliberación. Bogotá, Colombia: Ediciones Uniandes.

De Bufalá, P. (2010). Crisis del parlamentarismo. México D. F.: Instituto Tecnológico y de Estudios Superiores de Monterrey.

Echavarría Olózaga, H. (2009). Reforma política y reelección. Bogotá, Colombia: Instituto de Ciencia Política.

Escandón, M. (2011). Cuestionamientos a la representación identitaria en el Congreso de Colombia. Bogotá, Colombia: Ediciones Uniandes.

García-Peña, D. (Enero-Junio, 1993). El viejo Congreso y la paz. Una breve historia del papel de la rama legislativa en los procesos de paz de Betancur y Barco. Historia Crítica, 07, 45-49.

García Villegas, M. y Uprimny, R. (2006). El control judicial de los estados de excepción en
Colombia. Bogotá, Colombia: DeJusticia.

Hamilton, A., Madison, J. y Jay, J. (1943). El Federalista. México D. F.: Fondo de Cultura Económica.

Herrera Llanos, W. (2003). La rama legislativa del poder público en Colombia. Barranquilla, Colombia: Uninorte.

Iturralde, M. (Junio, 2003). Guerra y derecho en Colombia: el decisionismo político y los estados de excepción como respuesta a la crisis democrática. Revista de Estudios Sociales, 15, 29-46.

Ladrón de Guevara, A. (2002). Degradación o cambio: evolución del sistema político colombiano. Bogotá, Colombia: Norma.

López, C. (2010). El Pin está en la U. La Silla Vacía. Recuperado de: http://www.lasillavacia. com/elblogueo/clopez/9230/el-pin-esta-enla-u

López Michelsen, A. (2004). El sistema parlamentario. Bogotá, Colombia: Legis.

Montesquieu. (1977). Del espíritu de las leyes. Ciudad de México, México: Porrúa.

Naranjo, V. (2000). Teoría constitucional e instituciones políticas. Bogotá, Colombia: Temis.

Peces-Barba, G. (1986). Reflexiones sobre el Parlamento. Madrid, España: Universidad Complutense. 
Prieto, M. (Julio-Septiembre, 2010). La importancia de nuestros partidos políticos para el desarrollo de la democracia. Revista Política Colombiana, (5), 22-40.

Rodríguez-Raga, J. C. (2011). Cultura política de la democracia en Colombia. Bogotá, Colombia: Ediciones Uniandes.

Schmitt, C. (1926). La crisis de la democracia parlamentaria. Cambridge, E.E. U.U.: MIT Press.

Schumpeter, J. A. (1971). Capitalismo, socialismo y democracia. Madrid, España: Aguilar.
Semana. (2 de octubre de 2012). Se hundió proyecto que buscaba convertir la salud en derecho fundamental. Recuperado de http://www.semana.com/politica/hundioproyecto-buscaba-convertir-salud-derechofundamental/185769-3.aspx

Wills, L. (2009). ¿Juntos pero no revueltos? Partidos, candidatos y campañas en las elecciones legislativas de 2006 en Colombia. Bogotá, Colombia: Ediciones Uniandes-Ceso. 